\title{
A National height-age model for Pinus radiata in New Zealand
}

Mina van der Colff ${ }^{1}$ and Mark O Kimberley ${ }^{2^{*}}$

\begin{abstract}
Background: Historically, a series of regional height-age functions have been used to predict height growth of Pinus radiata in New Zealand. However, for some regions there are no available models while other regions have more than one available model.

Methods: To remedy this situation, a new system of height-age growth models for $P$. radiata in New Zealand was developed from a nationwide database using nonlinear mixed modelling techniques.

Results: When tested by cross validation, a simple national model performed poorly compared to a series of models with different parameters for each region, demonstrating the existence of regional differences in the form of the height-age relationship. Examination of the regional behaviour suggested that the effect of temperature is best represented by a common-asymptote family of curves, while other factors such as water availability and nutrition appear to be better represented by anamorphic families of curves. A national height-age model reflecting this behaviour was developed. This model is a polymorphic form of the Bertalanffy-Richards function, with the slope parameter expressed as a linear function of latitude and elevation.
\end{abstract}

Conclusions: This general model was found to perform better than a series of regional models, and is therefore recommended as a general purpose height-age model for P. radiata in New Zealand.

Keywords: Height-age curves, Height, Growth model, Site index, Latitude, Elevation, Pinus radiata

\section{Background}

Plantation forests in New Zealand cover approximately 1.7 million hectares (Ministry for Primary Industries, 2012), about 6\% of the land area. Within this forest, Pinus radiata D. Don, is by far the dominant species, occupying about $90 \%$ of the plantation forest area. The ability to accurately forecast growth is important for the efficient management of forests, for exploring management options and silvicultural alternatives, and for guiding forest policy. To achieve this for $P$. radiata in New Zealand, a number of stand-level empirical growth models have been developed. An important component in any stand-level growth model is the height-age function which predicts height growth and allows height to be projected forward in time from a measurement.

Most height-age functions require an estimate of Site Index $(S I)$ to allow the model to adjust the height growth

\footnotetext{
* Correspondence: Mark.Kimberley@scionresearch.com

${ }^{2}$ Forest Science, Scion, Rotorua, New Zealand

Full list of author information is available at the end of the article
}

trajectory for site effects. Site Index is defined as the height of the dominant trees in the stand at a reference base age, and is not greatly influenced by stand density. For $P$. radiata in New Zealand, the base age is usually set at 20 years after planting. The height variable generally used in evaluating the dominant height in $P$. radiata is Mean Top Height (MTH), which is defined as the mean height of the 100 largest diameter stems of well-formed trees per hectare (Burkhart \& Tennent 1977). Site Index is usually determined for a particular stand by applying an inverse form of the height-age function to a height-age measurement. These definitions of SI and MTH were used in the current study.

The first published system for predicting height growth of $P$. radiata in New Zealand was provided by a SI chart published by Lewis (1954). However, Beekhuis (1966) recommended that local height-age curves should be fitted leading to the development of numerous localised curves. Regression methods of fitting height-age functions began to be applied in the 1970s, for example by Bailey \&

\section{实}

(c) 2013 van der Colff and Kimberley; licensee Springer. This is an Open Access article distributed under the terms of the Creative Commons Attribution License (http://creativecommons.org/licenses/by/2.0), which permits unrestricted use, distribution, and reproduction in any medium, provided the original work is properly cited. 
Clutter (1974) who developed Site Index equations for the Central North Island of New Zealand, the region with the greatest resource of $P$. radiata.

A more comprehensive analysis of height growth was provided by Burkhart \& Tennent (1977) who fitted heightage curves to permanent sample plot data from throughout New Zealand. They used the Bertalanffy-Richards function (Richards, 1959): $H=a(1-\exp (b T))^{c}$. A polymorphic form of the function in which both the asymptote and slope parameters were expressed as functions of $S I$ was used. After experimenting with various functions, they chose, $a=S I /\left(1-\exp \left(20 b_{1} S I\right)\right)^{c}$ and $b=b_{1} S I$. To estimate the parameters $c$ and $b_{1}$, they firstly estimated $S I$ for each plot using height measurements close to age 20, and then fitted the modified Bertalanffy-Richards equation using a standard nonlinear regression procedure. They found that there was significant regional variation among the parameters, and ultimately divided their data into eight regions, with separate coefficients estimated for each region.

A series of regional growth models incorporating height-age functions were developed during the 1980s (Garcia, 1979, 1983, 1984, 1988; Shula, 1989). These models were also based on the Bertalanffy-Richards function. To fit the function, the derivative of height growth was expressed as a function of height, and parameters were estimated using a maximum likelihood procedure, fitting height increment against height. For most of these regional models, the asymptote and shape parameters, $a$ and $c$, were held constant with $b$ varying locally, creating a family of polymorphic curves having a common asymptote. However, in one model intended for use in coastal sands forests, an anamorphic function with $b$ and $c$ held constant, and $a$ varying locally, was found to perform better (Goulding, 1994). In contrast to these Bertalanffy-Richards models, a model developed for use in the Central North Island by Woollons \& Hayward (1985) was based on the Schumacher equation (Schumacher, 1939).

There is a general recognition that climate and soil greatly influence the height growth of $P$. radiata. For example, numerous studies have demonstrated relationships between $S I$ and climatic and/or soil variables. These have been carried out in New Zealand (Hunter \& Gibson, 1984; Palmer et al., 2009; Palmer et al., 2010; Watt et al., 2010), Australia (Truman et al., 1983), South Africa (Grey, 1989; Louw, 1991) and Chile (Schlatter, 1987). However, none of these studies considered whether the shape or form of the height-age relationship is influenced by environmental factors, and whether, for example, two stands from different sites with the same SI may have different growth trajectories.

In contrast, in the empirical fitting of height-age functions described above, there has been a tendency to recognise that there are regional differences in the shapes of these functions. These have generally been accommodated by fitting separate regional models rather than by incorporating environmental variables directly into the models. However, there has been little systematic analysis of how the shape of height-age curves varies between regions, and what environmental factors influence these.

This has led to a somewhat confusing situation for forest managers who are confronted with a series of different models with limited guidance on which ones are most appropriate for a given stand. There are currently some regions with no available model, and others for which more than one model has been developed. Some functions were developed using less advanced fitting procedures and less extensive data than are currently available, and this has most likely led to considerable variation in model performance. Because of this, there is clearly a need for a systematic analysis of regional differences in height-age curves. The objective of this study was to carry out such an analysis, and to develop either a single height-age function for $P$. radiata in New Zealand, or if necessary, a family of regional functions covering all sites in New Zealand.

\section{Methods}

\section{Data}

Suitable data were extracted from the Permanent Sample Plot (PSP) (Ellis \& Hayes, 1997) database maintained by Scion, Rotorua, New Zealand. Plots had to satisfy a number of criteria including:

- Each plot should contain growth data covering a suitable age range (with a minimum age range of 10 years). Plots with long measurement histories were considered to be of particular value.

- Stocking should fall within the normal range.

- An endeavour was made to obtain an adequate number of plots within each region of the country (preferably more than 50).

The variables required for the analysis were $\mathrm{MTH}$ and age. In addition, the following site information was also obtained for each plot: Location (North/South Island, region, latitude and longitude), elevation, and establishment date. Although this site information was limited, it should be noted that an important environmental variable, mean temperature, is largely controlled by latitude and elevation, with mean temperature reducing by approximately $1^{\circ} \mathrm{C}$ for every two degrees increase in latitude, and for every $200 \mathrm{~m}$ increase in elevation.

After extracting suitable data, they were screened for obvious anomalies. Suspect measurements and plots with high tree mortality were omitted from further analysis. 
Data was classified into the 16 local authority regions of New Zealand (Figure 1). As the Auckland and Nelson local authority regions are small, mostly urban, and contain limited planted forest, they were combined with the Northland and Tasman regions respectively. Data from nutrient-deficient coastal sand dune forests mainly in Northland/Auckland but also in the Waikato and Wanganui-Manawatu regions (e.g., Woodhill forest, in the west coast of the North Island) were classified separately. As there were only 4 PSPs in the Taranaki region and these were all classified as coastal sand forest, this region was not represented in the dataset.
A total of 3,639 plots were used in this analysis. Of these, 2,937 sample plots containing 23,813 measurements aged between 3 and 61 years old, were used as a model development data set, and a further 702 plots containing 5,699 measurements were used as a validation data set. The validation plots were chosen randomly from the dataset with the restriction that all plots in the three least well represented regions were retained in the model development set. Eighty plots had earlier been discarded due to missing information. A summary of the data in the development and validation data sets is shown in Table 1 and a summary by region is given in Table 2 .

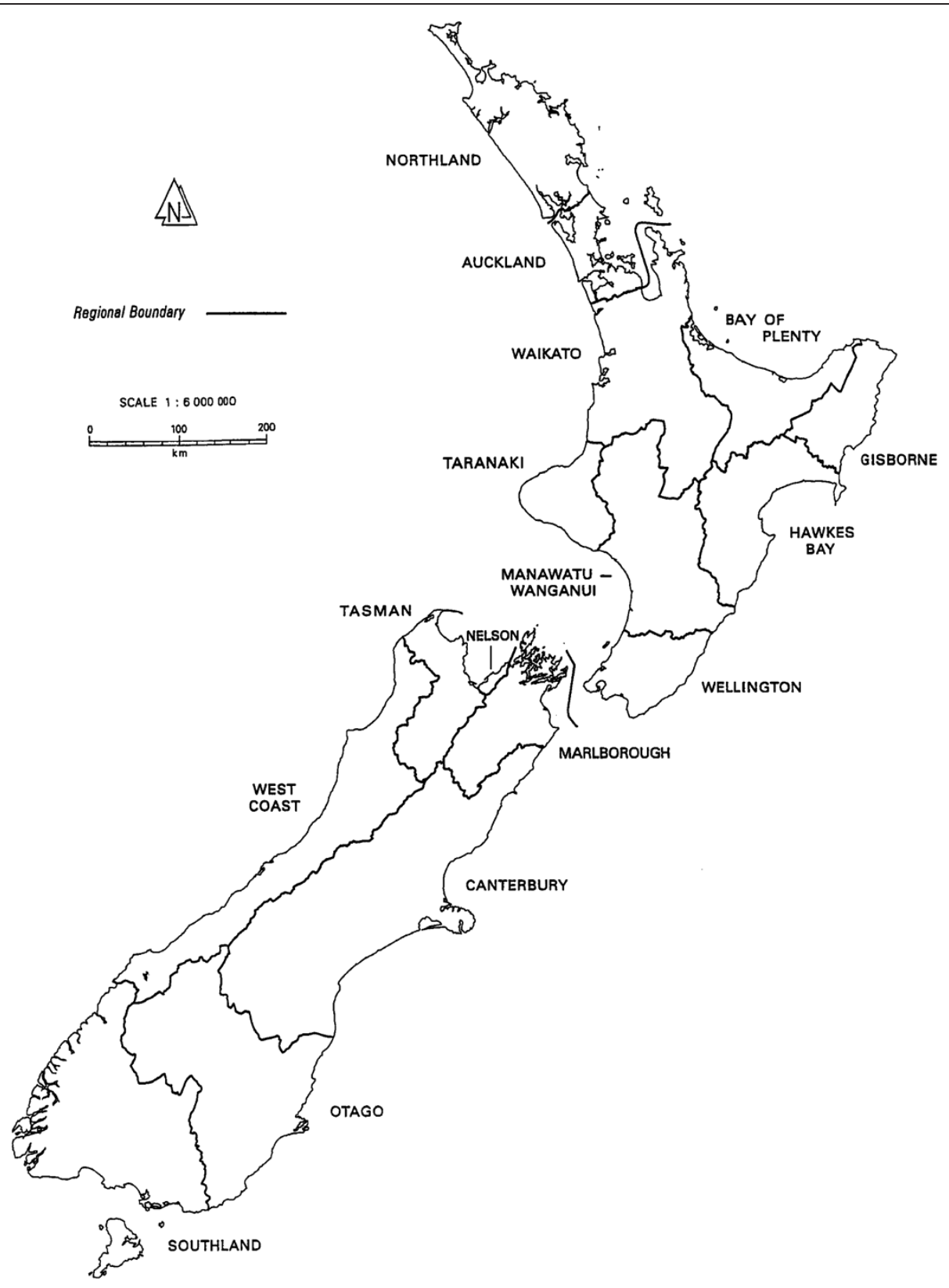

Figure 1 Map of New Zealand showing regions used in fitting regional forms of height-age models. 
Table 1 Summary of plots used in fitting and validating the height-age functions

\begin{tabular}{|c|c|c|c|c|c|c|c|c|}
\hline \multirow[b]{2}{*}{ Variable } & \multicolumn{4}{|c|}{ Modelling dataset } & \multicolumn{4}{|c|}{ Validation dataset } \\
\hline & Min & Mean & Max & Std. Dev. & Min & Mean & Max & Std. Dev. \\
\hline MTH (m) & 2.1 & 20.7 & 56.6 & 9.5 & 1.9 & 20.8 & 51.8 & 9.6 \\
\hline Age (yrs) & 3.0 & 14.8 & 60.5 & 7.4 & 3.0 & 14.9 & 59.1 & 7.5 \\
\hline$S I(m)$ & 8.9 & 28.5 & 43.4 & 4.6 & 14.2 & 28.9 & 42.4 & 4.5 \\
\hline Stocking (stems/ha) & 150 & 346 & 1000 & 165 & 150 & 329 & 1000 & 158 \\
\hline Latitude (oS) & 34.40 & 39.34 & 46.40 & 2.79 & 34.40 & 39.07 & 46.20 & 2.48 \\
\hline Longitude (E) & 152.70 & 174.58 & 178.30 & 2.26 & 152.70 & 174.83 & 177.90 & 2.33 \\
\hline Elevation (m, a.s.l.) & 0 & 270 & 1000 & 205 & 0 & 287 & 1000 & 210 \\
\hline
\end{tabular}

\section{Analysis}

A variety of sigmoidal height-age curves have been used to model height growth (see Zeide (1993) for a list of three- and four- parameter growth functions). In this study, the Bertalanffy-Richards, Schumacher, Hossfeld, and Weibull models were tested. The Bertalanffy-Richards or Chapman-Richards model (von Bertalanffy, 1949; Richards, 1959) is one of the most commonly used forestry growth equations, as is the Schumacher model (Schumacher, 1939). The Hossfeld model was originally proposed for describing tree growth as early as 1822 (Peschel, 1938), while the Weibull model is the cumulative form of a widely used probability distribution function that has proved to be a good model of tree growth (Yang et al., 1978).

Standard forms of these models and reparameterisations based on those used by Kimberley \& Ledgard (1998) are shown in Table 3. All models have an intercept of $0.25 \mathrm{~m}$, representing height at planting. The models express MTH (metres) as a function of age ( $\mathrm{T}$ in years). The reparameterisations use SI rather than an asymptote parameter. This is advantageous because expected-value parameters such as SI, which correspond to the fitted value of the response variable at a particular age, generally have good estimation properties (Ratkowsky, 1990). Also, the polymorphic forms of equations tested in this study required expressing one or more parameters as functions of $S I$, and the simplest means of achieving this was to use $S I$ as one of the parameters. It was also felt desirable for all parameters to have approximately symmetrical distributions. A random coefficient model with all three parameters treated as local random parameters for each plot was fitted using the SAS macro NLINMIX (Littell et al., 1996). The distributions of these parameters were then examined and transformations of parameters included in the reparameterised forms of each growth function as appropriate.

Table 2 Numbers of plots and measurements and means of important variables by region for the modelling and validation datasets

\begin{tabular}{|c|c|c|c|c|c|c|c|c|c|c|c|c|}
\hline \multirow[t]{2}{*}{ Region } & \multicolumn{6}{|c|}{ Modelling dataset } & \multicolumn{6}{|c|}{ Validation dataset } \\
\hline & Plots & Meas. & Age & SI & Lat. & Elev. & Plots & Meas. & Age & SI & Lat. & Elev. \\
\hline Northland/Auckland & 164 & 1,089 & 14 & 30.2 & 36.0 & 135 & 42 & 288 & 12 & 30.2 & 35.9 & 147 \\
\hline Waikato & 301 & 2,122 & 16 & 30.7 & 37.8 & 235 & 59 & 417 & 15 & 30.6 & 37.7 & 228 \\
\hline Bay of Plenty & 669 & 7,565 & 15 & 31.3 & 38.4 & 408 & 173 & 1,950 & 15 & 31.6 & 38.4 & 395 \\
\hline Gisborne & 70 & 490 & 11 & 31.3 & 38.2 & 338 & - & - & - & - & - & - \\
\hline Hawkes Bay & 269 & 1,881 & 11 & 30.6 & 39.5 & 369 & 75 & 568 & 11 & 30.0 & 39.4 & 378 \\
\hline Wanganui-Manawatu & 73 & 530 & 16 & 26.3 & 39.6 & 428 & 16 & 96 & 16 & 26.2 & 39.6 & 467 \\
\hline Wellington & 50 & 363 & 15 & 28.8 & 41.0 & 246 & - & - & - & - & - & - \\
\hline Marlborough & 80 & 546 & 12 & 28.9 & 41.3 & 232 & 27 & 193 & 12 & 28.1 & 41.3 & 224 \\
\hline Nelson/Tasman & 260 & 1,910 & 15 & 28.9 & 41.4 & 393 & 66 & 469 & 15 & 28.5 & 41.4 & 383 \\
\hline West Coast & 93 & 616 & 17 & 25.7 & 42.5 & 238 & 27 & 196 & 17 & 25.6 & 42.4 & 204 \\
\hline Canterbury & 162 & 1,198 & 14 & 24.0 & 43.3 & 297 & 39 & 277 & 14 & 24.7 & 43.3 & 291 \\
\hline Otago & 141 & 954 & 16 & 24.3 & 46.0 & 224 & 34 & 227 & 15 & 24.4 & 46.0 & 215 \\
\hline Southland & 65 & 668 & 15 & 27.1 & 45.8 & 207 & - & - & - & - & - & - \\
\hline Coastal sand & 540 & 3,881 & 16 & 24.7 & 36.8 & 49 & 144 & 1,018 & 17 & 25.0 & 36.8 & 55 \\
\hline
\end{tabular}


Table 3 Standard (S) and reparameterised (R) forms of the height-age functions used in the study

\begin{tabular}{|c|c|c|}
\hline Growth function & Type & Equation \\
\hline \multirow[t]{2}{*}{ Bertalanffy-Richards } & $\mathrm{S}$ & MTH $=0.25+(c-0.25)(1-\exp (-a T))^{1 / b}$ \\
\hline & $\mathrm{R}$ & $\begin{array}{l}\text { MTH }=0.25+(S I-0.25)[(1-\exp (-a T)) / \\
(1-\exp (-20 a))]^{1 / b}\end{array}$ \\
\hline \multirow[t]{2}{*}{ Hossfeld } & S & $M T H=0.25+(c-0.25)\left(T^{b}\right) /\left(a+T^{b}\right)$ \\
\hline & $\mathrm{R}$ & $\begin{array}{l}M T H=0.25+(S /-0.25)(T / 20)^{b}\left[\left(a+20^{b}\right) /\right. \\
\left.\left(a+T^{b}\right)\right]\end{array}$ \\
\hline \multirow[t]{2}{*}{ Schumacher } & S & MTH $=0.25+(c-0.25) \exp \left(-a T^{-b}\right)$ \\
\hline & $\mathrm{R}$ & MTH $=0.25+(S I-0.25) \exp \left(a\left(1 / 20^{b}-1 / T^{b}\right)\right)$ \\
\hline \multirow[t]{2}{*}{ Weibull } & S & $M T H=0.25+(c-0.25)\left(1-\exp \left(-a T^{b}\right)\right)$ \\
\hline & $\mathrm{R}$ & $\begin{array}{l}\text { MTH }=0.25+(S /-0.25)\left[\left(1-\exp \left(-a T^{b}\right)\right) /\right. \\
\left.\left(1-\exp \left(-a 20^{b}\right)\right)\right]\end{array}$ \\
\hline
\end{tabular}

All models were fitted as nonlinear mixed models using the SAS macro NLINMIX. The algorithm implemented in this macro is similar to the first order method of Sheiner \& Beal (1985). It fits nonlinear models containing global, fixed-effect parameters, and local, normally distributed random effect-parameters. In this analysis, local parameters were estimated for each plot. Goodness of fit was assessed using Schwarz's Bayesian Information Criterion (BIC) (Schwarz, 1978), a measure widely used to compare nonlinear mixed models which accounts for the number of parameters when comparing models. Differences in BIC can be used to compare competing models, with better fitting models having smaller BIC values. A commonly used rule-of -thumb states that two models are indistinguishable if their BICs differ by less than 2, but when the BICs of competing models differ by more than 10 this is strong evidence in favour of the model with the smaller BIC.

Three model types were fitted:

- Type A: Simple national models. Both anamorphic and common-asymptote forms of all four models shown in Table 3 were tested along with a more general polymorphic form as described below.

- Type B: A more complex national model based on the best Type A form, but including site variables such as elevation and latitude in the formulation.

- Type C: A family of regional models for the regions shown in Figure 1 consisting of the same model forms used for Type A but with separate parameters estimated for each region.

For Type A models, both anamorphic and commonasymptote forms of all four functions were tested. The anamorphic form was based on the reparameterised form of each growth function (Table 3), with SI fitted as a local parameter varying between plots, while the shape $(b)$ and slope $(a)$ parameters were fitted as fixed global parameters. In the common-asymptote form, the standard form of each growth function (Table 3) was fitted using global asymptote $(c)$ and shape $(b)$ parameters, and a local slope (a) parameter. A more general polymorphic form based on the reparameterised forms (Table 3) was fitted in which $S I$ was fitted as a local parameter, and the shape and slope parameters were expressed as linear functions of $S I$. Various nonlinear functions of $S I$ for expressing the slope and shape parameters were also tested, but none of these clearly outperformed simple linear functions.

Type B models were developed as extensions of the general polymorphic Type A models. Firstly, the reparameterised forms of the growth functions (Table 3) were fitted with all three parameters treated as local random parameters. The parameters $a$ and $b$ were then plotted against available site variables as well as SI. Suitable functional forms were chosen on the basis of these plots, and the model re-fitted using these functions, and treating $S I$ as a local random parameter.

The Type $\mathrm{C}$ models were fitted using dummy variables for each region coded 1 for PSPs within the region and 0 otherwise. Three model forms were tested: an anamorphic form with separate shape and slope parameters for each region; a common-asymptote form with separate shape and asymptote parameters for each region and local slope parameter; and a general polymorphic form based on the reparameterised growth functions with $S I$ fitted as a local parameter, and with separate shape and slope parameters for each region which also contained linear terms in SI.

The precision of MTH prediction across a range of ages was examined by cross validation using the validation data set. To thoroughly test the performance of each model for a range of ages, height at a given age was predicted from an earlier measurement for each plot and compared with the actual height using the Root Mean Square Error (RMSE $=\sqrt{(y-\hat{y})^{2} / n}$, where $y$ is MTH and $\hat{y}$ is predicted MTH). This analysis was performed for starting ages of 10 to 30 years in steps of 5 years, and prediction ages from 5 years after the starting age to 35 years, also in steps of 5 years. The analysis was also performed using the model development dataset.

\section{Results}

The goodness-of-fit of all models tested is summarised using the Bayesian Information Criterion (BIC) in Table 4. Of the Type A models, for all growth functions the anamorphic form fitted substantially better than the common-asymptote form, although the general polymorphic form provided the best fit. Of the three Type A forms of the Bertalanffy-Richards function tested, predictions using the general polymorphic curve generally fell between the anamorphic and general polymorphic predictions for the same age and $S I$, but were always much 
Table 4 Bayesian information criteria (BIC) for different forms of height-age models

\begin{tabular}{clcccc}
\hline Type & Form & Bertalanffy-Richards & Hossfeld & Weibull & Schumacher \\
\hline A & Anamorphic & 79,458 & 79,528 & 79,538 & 80,742 \\
& Common-asymptote & 81,617 & 82,391 & 81,339 & 82,882 \\
& General polymorphic & 78,634 & 78,436 & 78,873 & 79,441 \\
\multirow{2}{*}{ B } & Polymorphic with site variables & 73,006 & 73,380 & 73,462 & 75,167 \\
C & Regional Anamorphic & 75,850 & 75,830 & 75,988 & 77,160 \\
& Regional common-asymptote & 73,461 & 75,335 & 74,409 & 78,190 \\
& Regional general polymorphic & 73,441 & 73,953 & 73,354 & 75,326 \\
\hline
\end{tabular}

Smaller values indicate better fitting models.

closer to the anamorphic than common-asymptote form (Figure 2a).

For anamorphic models, the Bertalanffy-Richards function performed best followed in order by the Hossfeld, Weibull and Schumacher models. However, for the general polymorphic form, the Hossfeld fitted slightly better than the Bertalanffy-Richards function. Of the four growth functions tested, the Schumacher function was always the poorest performing. Parameter estimates for the Type A anamorphic, common-asymptote, and general polymorphic forms of the Bertalanffy-Richards model are given in Table 5. The equation for the latter model is the reparameterised form of the function shown in Table 3 with the $a$ and $b$ parameters expressed as linear functions of $S I$ :

$$
\begin{aligned}
M T H= & 0.25+(S I-0.25)\left[\left(1-\exp \left(-\left(a_{0}+a_{1} S I\right) T\right)\right)\right. \\
& \left./\left(1-\exp \left(-20\left(a_{0}+a_{1} S I\right)\right)\right)\right]^{1 /\left(b_{0}+b_{1} S I\right)}
\end{aligned}
$$

The Type B models which contained additional terms for latitude and elevation achieved a considerable improvement in fit over any of the Type A models (Table 4). Type B models were derived by fitting random coefficient forms of the reparameterised functions, and plotting the parameters $a$ and $b$ against available site variables as well

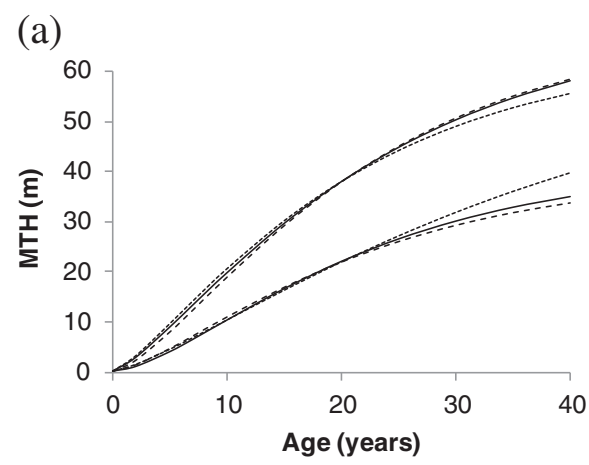

(b)
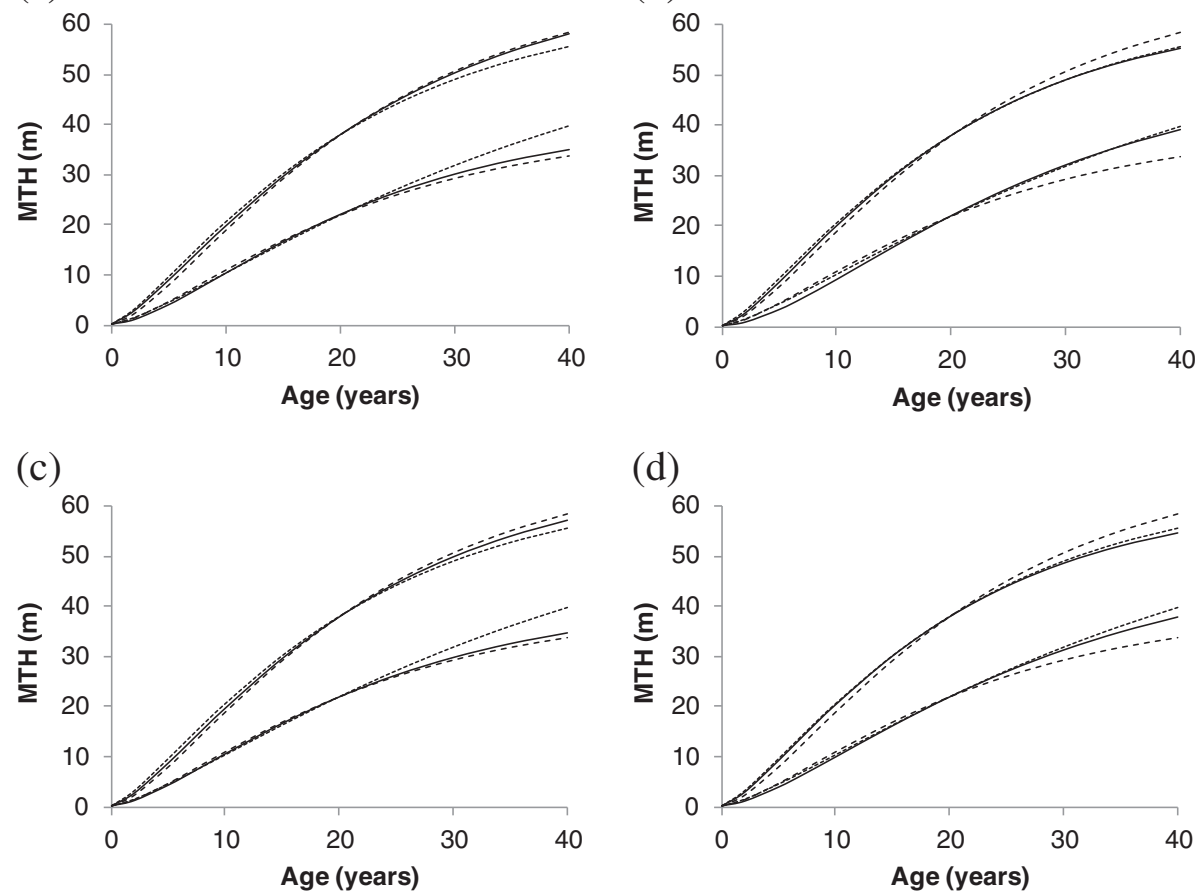

(d)

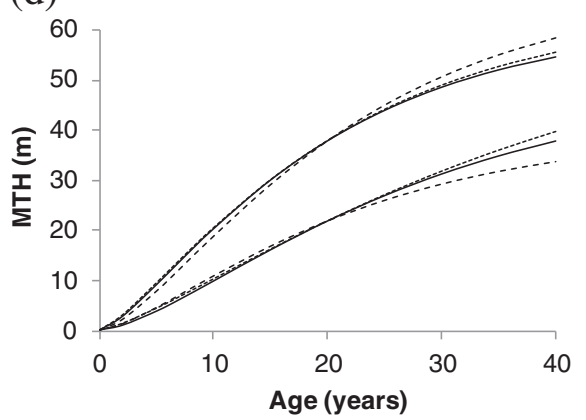

Figure 2 Height-age curves for different forms of the Bertalanffy-Richards height-age model. The solid lines show: (a) National Type A general polymorphic model; (b) Type C Bay of Plenty regional general polymorphic model; (c) Type B model at latitude $40^{\circ} \mathrm{S}$ and elevation $200 \mathrm{~m}$; (d) Type B model at latitude 40 S and elevation $20 \mathrm{~m}$ (upper line) and $500 \mathrm{~m}$ (lower line). In all cases, the dashed line is the Type A anamorphic model and the dotted line is the Type A common-asymptote model. Also in all cases, the upper 3 curves are at S/ $38 \mathrm{~m}$ and the lower group at SI $22 \mathrm{~m}$. 
Table 5 Parameter estimates with standard errors for Type A forms of the Bertalanffy-Richards function fitted to the national dataset

\begin{tabular}{lccc}
\hline Form & Parameter & Estimate & Std. Error \\
\hline Anamorphic & $a$ & 0.05695 & 0.00037 \\
& $b$ & 0.6406 & 0.0022 \\
Common-asymptote & $b$ & 0.7307 & 0.0024 \\
General polymorphic (Equation 1) & $c$ & 64.47 & 0.28 \\
& $a_{0}$ & 0.0693 & 0.0026 \\
& $a_{1}$ & $-4.66 \mathrm{E}-04$ & $0.86 \mathrm{E}-04$ \\
& $b_{0}$ & 0.388 & 0.016 \\
& $b_{1}$ & $8.58 \mathrm{E}-03$ & $0.54 \mathrm{E}-03$ \\
\hline
\end{tabular}

as SI. A linear relationship was observed between the slope $(a)$ parameter and both latitude and elevation and the model was re-fitted including this relationship, and treating $S I$ as a random parameter. Like the Type A general polymorphic form, the shape $(b)$ parameter of the Type B model was fitted as a linear function of $S I$, as the BIC indicated this performed significantly better than a model with a fixed slope parameter. Other more complex variations of Type B models were also tested including a version with the slope parameter fitted as a linear function of $S I$, elevation and latitude, and versions with the shape parameter fitted as functions of latitude and/or elevation, but these variations showed no improvement in fit. The equation for the chosen Type B form of the BertalanffyRichards function model is as follows:

$$
\begin{aligned}
M T H= & 0.25+(S I-0.25)[(1-\exp (-a T)) \\
& /(1-\exp (-20 a))]^{1 /\left(b_{0}+b_{1} S I\right)}
\end{aligned}
$$

where, $a=a_{0}+a_{1} L+a_{2} E, \quad L=$ Latitude $\left({ }^{0} S\right)$ and $E=$ Elevation (m). Parameter estimates are given in Table 6.

Type $\mathrm{C}$ regional models were obtained by fitting anamorphic, common-asymptote, and a general polymorphic form of each growth function, with separate parameters for each region. The equation for the general polymorphic form of the Type $\mathrm{C}$ regional BertalanffyRichards model is as follows:

$$
\begin{aligned}
M T H= & 0.25+(S I-0.25)\left[\left(1-\exp \left(-\left(a_{0 i}+a_{1} S I\right) T\right)\right)\right. \\
& \left./\left(1-\exp \left(-20\left(a_{0 i}+a_{1} S I\right)\right)\right)\right]^{1 /\left(b_{0 i}+b_{1} S I\right)}
\end{aligned}
$$

with regions indicated by the subscripts $i=1$ to 15 . Parameter estimates for the Type $\mathrm{C}$ regional common-asymptote and general polymorphic forms of the Bertalanffy model are given in Table 7.

The BIC of Type $\mathrm{C}$ models was consistently smaller than for the best Type A models indicating the existence
Table 6 Parameter estimates with standard errors for the Type B form of the Bertalanffy-Richards function (Equation 2) fitted to the national dataset

\begin{tabular}{ccc}
\hline Parameter & Estimate & Std. Error \\
\hline$a_{0}$ & 0.1409 & 0.0019 \\
$a_{1}$ & $-1.96 \mathrm{E}-03$ & $0.05 \mathrm{E}-03$ \\
$a_{2}$ & $-3.38 \mathrm{E}-05$ & $0.06 \mathrm{E}-05$ \\
$b_{0}$ & 0.5141 & 0.0058 \\
$b_{1}$ & $4.57 \mathrm{E}-03$ & $0.18 \mathrm{E}-03$ \\
\hline
\end{tabular}

of regional differences in height-age relationships (Table 4). For these regional models, the common-asymptote forms performed better than the anamorphic forms. However, the BIC for the Bertalanffy-Richards Type B model was smaller than that of any of the Type $C$ regional models. This result suggests that by including latitude and altitude in its formulation, this national model adequately accounts for regional differences in the heightage relationship.

The performance of the Bertalanffy-Richards models were next tested in various ways against the validation dataset which consisted of a random selection of 702 plots (19\%) out of the original dataset. Tests were conducted for Types A, B and C models to determine whether models of increasing complexity were justified when tested against independent validation data. The same tests were also performed using the model dataset. In the first series of tests measurements at varying starting ages were projected forward to some future age, and compared against an actual measurement at that age using the RMSE criteria. Generally, this confirmed that the nonlinear mixed modelling technique used in the study produced models with good levels of accuracy in estimating height for any given age. In almost all cases, these tests indicated that the Type B model performed best followed by the Type $\mathrm{C}$ model, with the Type A model invariably performing poorest (Table 8).

When these validation results were summarised by region, the Type $\mathrm{B}$ model outperformed the Type $\mathrm{C}$ model in about $50 \%$ of regions (Table 9), even though the latter model contained region-specific coefficients (Table 7). Although there were some regions where the Type B model had a slightly higher RMSE than the Type $\mathrm{C}$ model, the difference in performance between the two model forms in these regions was general minimal. Therefore, the Type B model would clearly be preferred over the Type $\mathrm{C}$ model, given its simplicity and the advantages of using a single national level model over a family of regional models.

Unlike the anamorphic or common asymptote forms of the Bertalanffy-Richards model, the general polymorphic form used for the Type B model cannot be converted 
Table 7 Parameter estimates with standard errors for Type C regional forms of the Bertalanffy-Richards function

\begin{tabular}{|c|c|c|c|c|c|c|c|c|}
\hline \multirow[t]{3}{*}{ Region } & \multicolumn{4}{|c|}{ Common-asymptote } & \multicolumn{4}{|c|}{ General polymorphic } \\
\hline & \multicolumn{2}{|c|}{$b_{i}$} & \multicolumn{2}{|c|}{$c_{i}$} & \multicolumn{2}{|c|}{$a_{o i}$} & \multicolumn{2}{|c|}{$b_{o i}$} \\
\hline & Est. & S.E. & Est. & S.E. & Est. & S.E. & Est. & S.E. \\
\hline Northland/Auckland & 0.710 & 0.005 & 56.9 & 0.5 & 0.0329 & 0.0028 & 0.442 & 0.019 \\
\hline Waikato & 0.684 & 0.004 & 58.1 & 0.3 & 0.0380 & 0.0026 & 0.381 & 0.018 \\
\hline Bay of Plenty & 0.657 & 0.002 & 61.1 & 0.2 & 0.0295 & 0.0026 & 0.399 & 0.018 \\
\hline Gisborne & 0.682 & 0.007 & 63.7 & 1.1 & 0.0228 & 0.0042 & 0.461 & 0.025 \\
\hline Hawkes Bay & 0.677 & 0.004 & 60.5 & 0.5 & 0.0213 & 0.0030 & 0.474 & 0.019 \\
\hline Wanganui-Manawatu & 0.653 & 0.007 & 60.4 & 0.7 & 0.0105 & 0.0025 & 0.537 & 0.018 \\
\hline Wellington & 0.640 & 0.009 & 60.8 & 0.8 & 0.0139 & 0.0039 & 0.501 & 0.028 \\
\hline Marlborough & 0.649 & 0.006 & 58.0 & 0.8 & 0.0253 & 0.0035 & 0.443 & 0.022 \\
\hline Nelson/Tasman & 0.638 & 0.004 & 57.8 & 0.4 & 0.0341 & 0.0027 & 0.382 & 0.018 \\
\hline West Coast & 0.631 & 0.007 & 52.7 & 0.6 & 0.0452 & 0.0034 & 0.355 & 0.020 \\
\hline Canterbury & 0.629 & 0.005 & 49.5 & 0.5 & 0.0373 & 0.0031 & 0.412 & 0.018 \\
\hline Otago & 0.594 & 0.005 & 54.6 & 0.5 & 0.0202 & 0.0023 & 0.467 & 0.017 \\
\hline Southland & 0.641 & 0.007 & 54.6 & 0.7 & 0.0242 & 0.0046 & 0.463 & 0.027 \\
\hline Coastal sand & 0.785 & 0.004 & 45.1 & 0.2 & 0.0457 & 0.0023 & 0.481 & 0.016 \\
\hline SI coefficient $\left(a_{1}\right.$ and $\left.b_{1}\right)$ & - & - & - & - & 8.73E-04 & $0.82 \mathrm{E}-04$ & 7.04E-03 & $0.55 \mathrm{E}-03$ \\
\hline
\end{tabular}

Estimates are shown for the common-asymptote and general polymorphic forms (Equation 3).

into an inverse equation for estimating SI directly from a height-age measurement. Instead, the following iterative procedure can be used. Firstly, using a starting value for $S I$ of $30, a$ and $b$ are calculated using Equation (2), and these values are then used to estimate SI using:

$$
\begin{aligned}
S I= & 0.25+(M T H-0.25)[(1-\exp (-20 a)) \\
& /(1-\exp (-a T))]^{1 / b}
\end{aligned}
$$

where MTH $(\mathrm{m})$ and $\mathrm{T}$ (years) are the height-age measurement. This estimate of SI is used to obtain a

\begin{tabular}{|c|c|c|c|c|c|c|c|}
\hline \multirow{2}{*}{$\begin{array}{l}\text { Measurement } \\
\text { age (years) }\end{array}$} & \multirow{2}{*}{$\begin{array}{l}\text { Prediction } \\
\text { age (years) }\end{array}$} & \multicolumn{3}{|c|}{ Validation dataset } & \multicolumn{3}{|c|}{ Model dataset } \\
\hline & & Type A & Type B & Type C & Type A & Type B & Type C \\
\hline \multirow[t]{5}{*}{10} & 15 & 0.97 & 0.84 & 0.84 & 0.95 & 0.83 & 0.82 \\
\hline & 20 & 1.43 & 1.18 & 1.21 & 1.53 & 1.28 & 1.31 \\
\hline & 25 & 1.80 & 1.38 & 1.52 & 1.98 & 1.57 & 1.72 \\
\hline & 30 & 1.94 & 1.45 & 1.70 & 2.18 & 1.71 & 1.71 \\
\hline & 35 & 2.48 & 1.49 & 2.14 & 2.68 & 1.24 & 1.33 \\
\hline \multirow[t]{4}{*}{15} & 20 & 1.05 & 0.95 & 0.98 & 1.11 & 1.02 & 1.02 \\
\hline & 25 & 1.59 & 1.35 & 1.47 & 1.73 & 1.42 & 1.51 \\
\hline & 30 & 1.91 & 1.49 & 1.69 & 1.99 & 1.64 & 1.68 \\
\hline & 35 & 2.93 & 1.90 & 2.29 & 2.96 & 1.50 & 1.60 \\
\hline \multirow[t]{3}{*}{20} & 25 & 1.25 & 1.13 & 1.18 & 1.35 & 1.18 & 1.21 \\
\hline & 30 & 1.76 & 1.48 & 1.58 & 1.91 & 1.49 & 1.49 \\
\hline & 35 & 2.90 & 2.26 & 2.46 & 3.27 & 1.93 & 1.87 \\
\hline \multirow[t]{2}{*}{25} & 30 & 1.20 & 1.16 & 1.22 & 1.39 & 1.28 & 1.35 \\
\hline & 35 & 1.98 & 1.92 & 2.07 & 2.59 & 1.77 & 1.76 \\
\hline 30 & 35 & 1.03 & 1.41 & 1.44 & 1.04 & 1.37 & 1.47 \\
\hline
\end{tabular}

Table 8 RMSE $(\mathrm{m})$ of predictions from varying starting and prediction ages for both the validation and model datasets

Predictions are made for Type A, B and C general polymorphic forms of the Bertalanffy-Richards function. The smallest RMSE for each dataset is indicated in boldface. 


\begin{tabular}{|c|c|c|c|c|}
\hline \multirow[t]{2}{*}{ Region } & \multicolumn{2}{|c|}{ Validation dataset } & \multicolumn{2}{|c|}{ Model dataset } \\
\hline & Type B & Type C & Type B & Type C \\
\hline Northland/Auckland & 1.64 & 1.55 & 1.67 & 1.40 \\
\hline Bay of Plenty & 1.67 & 1.67 & 1.31 & 1.53 \\
\hline Waikato & 1.60 & 1.71 & 1.46 & 1.54 \\
\hline Gisborne & $\mathrm{n} / \mathrm{a}$ & $\mathrm{n} / \mathrm{a}$ & 0.72 & 0.77 \\
\hline Hawkes Bay & 1.14 & 1.10 & 1.09 & 1.07 \\
\hline Wanganui-Manawatu & 1.57 & 1.45 & 1.10 & 1.05 \\
\hline Wellington & $\mathrm{n} / \mathrm{a}$ & $\mathrm{n} / \mathrm{a}$ & 1.09 & 1.09 \\
\hline Marlborough & 1.20 & 1.41 & 1.06 & 1.10 \\
\hline Nelson/Tasman & 1.12 & 1.32 & 0.97 & 1.12 \\
\hline West Coast & 1.32 & 1.33 & 1.31 & 1.48 \\
\hline Canterbury & 1.15 & 1.11 & 0.99 & 0.93 \\
\hline Otago & 0.94 & 1.07 & 1.02 & 0.92 \\
\hline Southland & $\mathrm{n} / \mathrm{a}$ & $\mathrm{n} / \mathrm{a}$ & 0.76 & 0.63 \\
\hline Coastal sand & 1.42 & 1.36 & 1.44 & 1.41 \\
\hline
\end{tabular}

For each region, the smallest RMSE for each dataset is indicated in boldface.

new estimate of $b$ and the procedure is repeated until SI has been estimated to a sufficient level of accuracy. At most, 10 iterations are required to estimate $S I$ to two decimal places. Although this introduces an additional layer of complexity in the use of the model, it is clearly justified by the superior performance of the model.

\section{Discussion}

In this study, different height-age model forms were found to be appropriate for models fitted for $P$. radiata at a national level, and at a regional level. When a general polymorphic model was fitted to a nationwide dataset, its behaviour was much closer to the anamorphic than the common-asymptote form (Figure 2a). Conversely, when a series of regional height-age models was fitted, they tended more to the common-asymptote form (Figure $2 \mathrm{~b}$ ). Furthermore, the series of regional models fitted much better overall than the simple national model. This behaviour validates the decision to generally use common-asymptote models for the family of regional height-age models developed in the 1980s (Garcia, 1979, 1983, 1984, 1988; Shula, 1989). However, given the better performance of the anamorphic form at the national level, at first sight the superior performance of commonasymptote models at the regional level is puzzling.

It seems likely that the contrasting model behaviour at the national and regional scales must reflect differences in how various environmental variables influence $P$. radiata height growth. The $S I$ of this species is known to be strongly influenced by a number of environmental variables. Principally among these is air temperature, with SI decreasing with reducing temperature from a maximum at a mean annual temperature of approximately $13^{\circ} \mathrm{C}$ which is typical of lower elevation sites in the central North Island (Hunter \& Gibson, 1984; Watt et al., 2010; Palmer et al., 2010). Other factors affecting SI reported by one or more of these studies include available root zone water storage, various measures of soil nutrition, and mean wind speed. The effect of temperature on $S I$ is clearly apparent in our dataset, with $S I$ averaging $30-31 \mathrm{~m}$ in the Northland/Auckland and Waikato regions of the North Island, but only 24-27 $\mathrm{m}$ in the cooler Otago and Southland regions of the South Island (Table 2).

A careful examination of the regional behaviour of $P$. radiata height-age models suggests that the effect of temperature is better represented by a common-asymptote rather than an anamorphic family of curves. For example, in the warmer Northland/Auckland and Waikato regions, the mean $S I$ is $30.5 \mathrm{~m}$ (Table 2) and the mean asymptote is $57.6 \mathrm{~m}$ (common-asymptote model $c$ parameter, Table 7), implying that $53 \%$ of asymptotic height is achieved at age 20 years. In contrast, in the cooler Otago and Southland regions, the mean $S I$ and asymptote are $25.7 \mathrm{~m}$ and $54.6 \mathrm{~m}$ respectively, implying that only $47 \%$ of ultimate height is achieved at age 20 years. A similar general trend of slower height development on cooler sites is apparent in other regions with, for example, the higher elevation forests in the Wanganui-Manawatu region only achieving $44 \%$ of their asymptotic height at age 20 years.

A tendency for height to develop more slowly with reducing temperature can also be seen within regions. For example, within the Bay of Plenty region in the North Island, there is a strong altitudinal gradient from coastal sites where $S I$ can be greater than $35 \mathrm{~m}$ to cooler elevated inland sites where $S I$ may only be $25 \mathrm{~m}$ (Palmer et al., 2010). When the Bertalanffy-Richards model was fitted separately to the Bay of Plenty data (analysis not shown), the common-asymptote form was strongly favoured over the anamorphic form, with a slight further improvement in fit provided by the general polymorphic form. Using the polymorphic model, the asymptotes for SI $25 \mathrm{~m}$ and $35 \mathrm{~m}$ are $55.9 \mathrm{~m}$ and $59.0 \mathrm{~m}$ respectively, implying that respectively $45 \%$ and $59 \%$ of asymptotic height are achieved at age 20 years.

However, it appears that, environmental variables other than temperature may have a scaling effect rather than altering the rate of height development, and are therefore better represented by an anamorphic rather than a common-asymptote family of curves. The clearest example of this is seen by comparing the nutrient deficient coastal sand sites in the Northland/Auckland and Waikato regions of the North Island with more fertile clay soils in the same regions. The average $S I$ and asymptote of the coastal sand forests are $24.7 \mathrm{~m}$ (Table 2) and $45.1 \mathrm{~m}$ 
(Table 7) respectively, implying they achieve $55 \%$ of asymptotic height by age 20 years, while as noted above, more fertile sites in these regions achieve 53\% of maximum height at the same base age. Therefore, a model performing well on both coastal sand and clay sites in the northern North Island would have to approximate the anamorphic form. Another example is provided by two lower productivity South Island regions, Canterbury (SI $24 \mathrm{~m})$ which has lowest root-zone water availability, and the nutrient deficient West Coast (SI 25.7). Both these regions achieve $49 \%$ of their asymptotic height at age 20 years, very similar to the $50 \%$ achieved in the more productive Marlborough, Nelson and Southland regions.

In summary, it appears that temperature effects on $P$. radiata height growth may be better approximated by a family of common-asymptote curves, while the effects of other environmental factors such as nutrition and water availability may be better represented by an anamorphic family of curves. Reducing temperature causes a slowing in the growth rate whereas poor nutrition or insufficient water results in a downward scaling of the entire height-age curve, but not necessarily any slowing in the rate of development relative to the asymptote. This description is somewhat simplistic as in addition to a slowing in growth rate, there is also some decrease in the asymptote on cooler sites, and there is, therefore, merit in using a general polymorphic family of curves rather than the simpler common-asymptote form to represent the affect of temperature on height growth.

Given the above conclusions, the reason for the superior performance of the Type B model (Equation 3) becomes apparent. The slope (a) parameter of this model is a function of elevation and latitude which, in combination, account for temperature. A change in $S I$ with latitude and elevation remaining constant would represent a change in productivity resulting from a site variable other than temperature. This situation produces behaviour similar to that of an anamorphic family of curves (Figure 2c). However, if the change in SI is caused by temperature (associated with a corresponding alteration in elevation and/or latitude), the resultant behaviour is closer to that of a common-asymptote than an anamorphic family of curves. This can be seen by comparing the model behaviour for two hypothetical sites at latitude $40^{\circ} \mathrm{S}$, one a warm, lower elevation site with high $S I$, and the other a cool, elevated site with low SI (Figure 2d).

\section{Conclusions}

Accurate estimation of height growth is essential in stand growth assessment. The nonlinear mixed modelling technique used in this study produced models with good levels of accuracy in estimating height for any given age. A national height-age model for $P$. radiata in New Zealand was developed which performed favourably compared with individual regional models, and is thus recommended for use as a general purpose height model. The model includes latitude and elevation in its formulation to account for differences in the pattern of height growth with temperature.

\section{Competing interests}

The authors declare that they have no competing interests.

\section{Authors' contributions}

MC carried out the analysis and drafted the manuscript; MK oversaw the study, assisted in the analysis, and completed the manuscript. Both authors read and approved the final manuscript.

\section{Acknowledgements}

We gratefully acknowledge assistance provided by Carolyn Andersen for extracting suitable data from the Scion Permanent Sample Plot system. This study was funded by the Ministry of Research, Science and Technology.

\section{Author details}

${ }^{1} 7$ Permien Street, Norman Gardens QLD 4701, Australia. ${ }^{2}$ Forest Science, Scion, Rotorua, New Zealand.

Received: 26 March 2013 Accepted: 26 March 2013

Published: 15 May 2013

\section{References}

Bailey, RL, \& Clutter, JL. (1974). Base-age invariant polymorphic site curves. Forest Sci, 20, 155-159.

Beekhuis, J. (1966). Prediction of yield and increment in Pinus radiata stands in New Zealand. Tech Pap For Res Inst N Z For Serv, 49, 40.

Burkhart, HE, \& Tennent, RB. (1977). Site index equations for radiata pine in New Zealand. N Z J For Sci, 7, 408-416.

Ellis, JC, \& Hayes, JD. (1997). Field guide for sample plots in New Zealand Forests (FRI Bulletin No. 186). Rotorua, New Zealand: New Zealand Forest Research Institute Limited.

Garcia, O. (1979). Forest Mensuration and Management Systems, Forest Research Institute, Rotorua, New Zealand. In DE Elliot (Ed.), Mensuration systems for forest management planning (Forest Research Institute Symposium, Vol. 20, pp. 315-334). New Zealand: New Zealand Forest Service.

Garcia, O. (1983). A stochastic differential equation model for the height growth of forest stands. Biometrics, 39, 1059-1072.

Garcia, O. (1984). New class of growth models for even-aged stands: Pinus radiata in Golden Downs Forest. N Z J For Sci, 14, 65-88.

Garcia, O. (1988). Experience with advanced growth modelling methodology. In AR Ek, SR Shifley, \& TE Burke (Eds.), Forest Growth Modelling and Prediction (USDA Forest Service General Technical Report NC, Vol. 120).

Goulding, CJ. (1994). Development of growth models for Pinus radiata in New Zealand - experience with management and process models. For Ecol Manage, 69, 331-343.

Grey, DC. (1989). A site-growth study of Pinus radiata in the Southern Cape. South Afr For J, 150, 32-39.

Hunter, IR, \& Gibson, AR. (1984). Predicting Pinus radiata site index from environmental variables. N Z J For Sci, 14, 53-64.

Kimberley, MO, \& Ledgard, NJ. (1998). Site index curves for Pinus nigra grown in the south island high country, New Zealand. N Z J For Sci, 28, 389-399.

Lewis, ER. (1954). Yield of unthinned Pinus radiata in New Zealand. For Res Note N Z For Serv, 1(10).

Littell, RC, Milliken, GA, Stroup, WW, \& Wolfinger, RD. (1996). SAS system for mixed models (Chapter, Vol. 12, pp. 463-489). Cary, North Carolina (USA): SAS Institute Inc.

Louw, JH. (1991). The relationship between site characteristics and Pinus radiata growth on the Tsitsikamma plateau, South Africa. South Afr For J, 158, 37-45.

Ministry for Primary Industries. (2012). National exotic forest description as at 1 April 2012. Wellington, New Zealand: Ministry for Primary Industries.

Palmer, DJ, Höck, BK, Kimberley, MO, Watt, MS, Lowe, DJ, \& Payn, TW. (2009). Comparison of spatial prediction techniques for developing Pinus radiata productivity surfaces across New Zealand. For Ecol Manage, 258, 2046-2055. 
Palmer, DJ, Watt, MS, Kimberley, MO, Höck, BK, Payn, T, \& Lowe, DJ. (2010). Mapping and explaining the productivity of Pinus radiata in New Zealand. N.Z. J For, 55(1), 15-19.

Peschel, W. (1938). Mathematical methods for growth studies of trees and forest stands and the results of their application. Tharandter Forstliches Jahrburch, 89, 169-247. In German.

Ratkowsky, DA. (1990). Handbook of nonlinear regression models. New York: Marcel Dekker

Richards, FJ. (1959). A flexible growth function for empirical use. J Exp Bot, 10, 290-300.

Sheiner, LB, \& Beal, SL. (1985). Pharmacokinetic parameter estimates from several least squares procedures: Superiority of extended least squares. J Pharmacokinet Biopharm, 13, 185-201.

Schlatter, JE. (1987). Soil fertility and the development of Pinus radiata. Bosque, $8,13-19$

Schumacher, FX. (1939). A new growth curve and its application to timber-yield studies. J For, 37, 819-820

Schwarz, GE. (1978). Estimating the dimension of a model. Ann Stat, 6(2), 461-464.

Shula, RG. (1989). Stand growth model with P fertilizer effects for radiata pine on clay soil (FRI Bulletin No. 148) (p. 62). Rotorua, New Zealand: Ministry of Forestry.

Truman, R, Humphreys, FR, \& Lambert, MJ. (1983). Prediction of site index for Pinus radiata at Mullions Range State Forest, New South Wales. Aust Forest Res, 13, 207-215

von Bertalanffy, L. (1949). Problems of organic growth. Nature, 163(4135), 156-158. Watt, MS, Palmer, DJ, Kimberley, MO, Höck, BK, Payn, TW, \& Lowe, DJ. (2010). Development of models to predict Pinus radiata productivity throughout New Zealand. Can J For Res, 40(3), 488-499.

Woollons, RC, \& Hayward, WJ. (1985). Revision of a growth and yield model for radiata pine in New Zealand. For Ecol Manage, 11, 191-202.

Yang, RC, Kozak, A, \& Smith, JHG. (1978). The potential of Weibull-type functions as flexible growth curves. Can J For Res, 8, 424-431.

Zeide, B. (1993). Analysis of growth equations. Forest Sci, 39, 594-636.

doi:10.1186/1179-5395-43-4

Cite this article as: van der Colff and Kimberley: A National height-age model for Pinus radiata in New Zealand. New Zealand Journal of Forestry Science 2013 43:4

\section{Submit your manuscript to a SpringerOpen ${ }^{\circ}$ journal and benefit from:}

- Convenient online submission

- Rigorous peer review

- Immediate publication on acceptance

- Open access: articles freely available online

- High visibility within the field

- Retaining the copyright to your article

Submit your next manuscript at $\gg$ springeropen.com 